Article

\title{
Success Factors in Management of Development Projects
}

\author{
Yovana Clarivel Surco-Guillen ${ }^{1,2, *}$, Javier Romero ${ }^{1}\left[\right.$, Rocío Rodríguez-Rivero ${ }^{1}\left(\mathbb{C}\right.$ and Isabel Ortiz-Marcos ${ }^{1}(\mathbb{C}$ \\ 1 Department of Organization Engineering, Business Administration and Statistics, Universidad Politécnica de \\ Madrid, C/José Gutiérrez Abascal 2, 28006 Madrid, Spain; javier.romero@upm.es (J.R.); \\ rocio.rodriguez@upm.es (R.R.-R.); isabel.ortiz@upm.es (I.O.-M.) \\ 2 Faculty of Science and Engineering, Pontifical Catholic University of Peru, 1801 Universitaria Avenue, \\ San Miguel, Lima 15088, Peru \\ * Correspondence: yovana.surco.guillen@alumnos.upm.es
}

Citation: Surco-Guillen, Y.C.;

Romero, J.; Rodríguez-Rivero, R.;

Ortiz-Marcos, I. Success Factors in

Management of Development

Projects. Sustainability 2022, 14, 780.

https://doi.org/10.3390/su14020780

Academic Editor: António Abreu

Received: 26 November 2021

Accepted: 5 January 2022

Published: 11 January 2022

Publisher's Note: MDPI stays neutral with regard to jurisdictional claims in published maps and institutional affiliations.

Copyright: (c) 2022 by the authors Licensee MDPI, Basel, Switzerland. This article is an open access article distributed under the terms and conditions of the Creative Commons Attribution (CC BY) license (https:// creativecommons.org/licenses/by/ $4.0 /)$.

\begin{abstract}
From the reports of the Inter-American Development Bank (IDB) Office of Evaluation and Oversight (OVE), a limited analysis of the factors affecting the execution of development cooperation projects was identified. Thanks to the review of scientific articles by renowned authors, effectiveness, relevance, competencies and motivation, sustainability, risk management, and additionality were evaluated using the analysis of relationships between variables and causality using IBM SPSS and fsQCA 3.0 software, respectively. As a result, a model was obtained that relates the components, factors, and roles that make up the stakeholder matrix. It was concluded that the effectiveness factor has a significant relationship with the success of a project; however, this could not be possible without a good development of sustainability and risk management, the latter being a necessary and sufficient condition for success in this type of projects. Currently, risk management has not only become a necessity nowadays, but the improvement of risk management will increase sustainability in project management, the main factors for the success of a project.
\end{abstract}

Keywords: critical success factors; participation analysis; relationship; causality; development cooperation projects; Inter-American Development Bank

\section{Introduction \\ 1.1. Context of Cooperation Projects}

The concepts of international cooperation have been subject to change. As mentioned in the journal Ciencias Estratégicas, "there has been a shift from assistance and a purely humanitarian process to an act of co-responsibility or partnership; from unilateral responsibility to joint, collaborative and participatory responsibility, and from a simple transfer to accompaniment and empowerment" [1]. Therefore, in this research, international cooperation is understood as the set of organized actions that energize processes that contribute to the development of communities or sectors of the population to find solutions and benefits through the exchange of technology, knowledge, skills, resources, and experiences, and to improve the living conditions and development of populations.

Since 1945, during World War II, with the signing of the United Nations Charter and the beginning of the Cold War, the need for and importance of international cooperation arose, which served not only as a fundamental tool to maintain peace and security during the war years but also to make international treaties, and even served as a strategy to influence between countries. Europe created the World Bank in 1944 to recover from the war, and in the 1950s other organizations were created to grant loans to developing countries, such as the International Development Association, the IDA, and the Inter-American Development Bank in 1959. From 1960 onwards, other multilateral organizations were created, such as the Organization for Economic Cooperation and Development (OECD), the Non-Aligned Movement (NAM), the Development Bank of Latin America (CAF), and the European Union (EU) [2]. 


\subsection{Necessity and Motivation}

Currently, the classification made by the international cooperation system to implement development projects is divided into low, lower-middle, upper-middle, and high-income countries. Low-income economies are defined as those with a Gross Net Income (GNI) per capita, calculated according to the World Bank Atlas method, of USD 1.035 or less in 2019. These countries are considered a priority for the international development cooperation system and, therefore, are classified as recipients of funds, while lower-middle-income economies are those with a GNI per capita between USD 1.036 and 4.045; upper-middle-income economies are those with a GNI per capita between USD 4.046 and 12.535; high-income economies are those with a GNI per capita of USD 12.536 or more [3].

As shown in Table 1, until 2021, Haiti has been the only country in Latin America considered as low income. All other countries in the region are in the lower-middle-income category (Bolivia, El Salvador, Honduras, Nicaragua) and upper middle income (Argentina, Belize, Brazil, Colombia, Costa Rica, Cuba, Dominica, Dominican Republic, Ecuador, Grenada, Guatemala, Guyana, Jamaica, Mexico, Paraguay, Peru, Saint Lucia, Saint Vincent and the Grenadines, Suriname, Venezuela). In the high-income classification are Antigua and Barbuda, Aruba, The Bahamas, Barbados, British Virgin Islands, Cayman Islands, Chile, Curaçao, Panama, Puerto Rico, Sint Maarten (part of the Kingdom of the Netherlands), St. Kitts and Nevis, St. Martin, Trinidad and Tobago, Turks and Caicos, Uruguay, U.S. Virgin Islands, a condition that removes them from the list of countries receiving development aid. This is how organizations such as the Spanish cooperation prioritizes projects in Haiti or at most in some middle-income countries. Therefore, the existence of other types of organizations such as Multilateral Banks, specifically the Inter-American Development Bank, which is focused on Latin America, is important.

Table 1. Per capita income ranking to 2021. Source: adapted from [4].

\begin{tabular}{cc}
\hline Level of Income & Countries \\
\hline $\begin{array}{c}\text { Low-income economies } \\
\text { (USD 1.035 or less) }\end{array}$ & Haiti \\
\hline $\begin{array}{c}\text { Lower-middle income economies } \\
\text { (Between USD 1.036 and 4.045) }\end{array}$ & Bolivia, El Salvador, Honduras, Nicaragua \\
\hline $\begin{array}{c}\text { Upper-Middle income economies } \\
\text { (Between USD 4.046 and 12.535) }\end{array}$ & $\begin{array}{c}\text { Argentina, Belize, Brazil, Colombia, Costa Rica, Cuba, Dominican } \\
\text { Republic, Ecuador, Grenada, Guatemala, Guyana, Jamaica, Mexico, } \\
\text { Paraguay, Peru, St. Lucia, St. Vincent and the Grenadines, Suriname, } \\
\text { Venezuela, St. Vincent and the Grenadines, Venezuela }\end{array}$ \\
\hline $\begin{array}{c}\text { High-income economies } \\
\text { (USD 12.536 or more) }\end{array}$ & $\begin{array}{c}\text { Antigua and Barbuda, Aruba, The Bahamas, Barbados, British Virgin } \\
\text { Islands, Cayman Islands, Chile, Curacao, Panama, Puerto Rico, Sint } \\
\text { Marten, St. Kitts and Nevis, St. Martin, Trinidad and Tobago, Turks } \\
\text { and Caicos Islands, Uruguay, United States Virgin Islands. }\end{array}$ \\
\hline
\end{tabular}

According to the 2020 report of the Spanish Agency for International Development Cooperation, AECID, more than 2600 Spaniards are professionally engaged in international cooperation and humanitarian action. However, in both the Project Completion Report (PCR) and the Extended Supervision Reports (XSR) analyzed by the IDB's Office of Evaluation and Monitoring (OVR) [4], the main object of study of the research, it was identified that there is a deficient analysis of the factors affecting project implementation, which makes it difficult to identify the factors that determine the results.

\subsection{Literature Review}

Table 2 shows the critical factors defined by different authors since 1987 whose articles have been obtained and analyzed in the Web of Science [5]. 
Table 2. Factors influencing the success of development projects, according to different authors. Source: adapted from [4].

\begin{tabular}{|c|c|c|c|}
\hline Author(s) & Year & & Factors \\
\hline Pinto, J.K \& Slevin D.P. [6] & 1987 & \multirow{4}{*}{ Operational Components } & Internal role interaction \\
\hline Belassi, W. \& Tukel, O.L. [7] & 1996 & & Expectations \\
\hline \multirow{2}{*}{ Westerveld E. [8] } & \multirow{2}{*}{2003} & & Motivational factors \\
\hline & & & Willingness to perform the work \\
\hline \multirow[t]{3}{*}{ Fortune, J. \& White, D. [9] } & 2006 & Emotional factors & $\begin{array}{l}\text { Understanding and acceptance of the objectives and } \\
\text { results }\end{array}$ \\
\hline & & \multirow{3}{*}{ Traditional aspects } & Times \\
\hline & & & Costs \\
\hline Baccarani D. [10] & 1999 & & Quality \\
\hline
\end{tabular}

Achievement of strategic objectives

Level of satisfaction by users in terms of their needs and problems solved

\begin{tabular}{llcl} 
Rodríguez R. \& Hesse M. [11] $2000 \quad$ Sustainability $\quad$ Sense of belonging \\
\cline { 3 - 4 }
\end{tabular}
Diallo A. \& Thuillier D. [12] $2004 \quad \begin{gathered}\text { Effectiveness and efficiency } \\ \text { achieved }\end{gathered}$
Degree of performance of the executing team

\begin{tabular}{c}
\hline Time management \\
\hline Cost management \\
\hline
\end{tabular}

Level of compliance with objectives

According to the conception that the members of the executing team have of value

Ba Khang, D. \& Lin Moe, T. [13] $2008 \quad$ Quality levels achieved

According to the conception that the members of the executing team have of the usefulness of the deliverables from the project.

Analyzing the extent to which their initial expectations have been met achieved

User satisfaction levels achieved

Analyzing the extent to which their expectations formed during project implementation have been met

Satisfaction of the target population with the goods and services generated.

Diallo A., Thuillier D. [12]

2004 Level of achievement of your objectives

Effectiveness and efficiency levels

$\begin{array}{r}\text { Competitive factors } \\ \hline \text { Motivational factors }\end{array}$

Leadership development

Ba Khang, D., Lin Moe, T. [13] 2008

$$
\text { Commitment }
$$

Enabling environment factors

Participation by the social groups involved

Good technical expertise of the executing teams

Efficient mechanisms for planning and monitoring of activities

Consistency with beneficiaries' needs

IDB's Development

Effectiveness Framework [14]
Alignment
Consistency with the country's development

Consistency with Multilateral Development Banks (MDBs) assistance strategy for the country 
Table 2. Cont.

\begin{tabular}{|c|c|c|c|}
\hline Author(s) & Year & & Factors \\
\hline \multirow{2}{*}{$\begin{array}{l}\text { IDB's Development } \\
\text { Effectiveness Framework [14] }\end{array}$} & \multirow[t]{2}{*}{2008} & Alignment & $\begin{array}{l}\text { Consistency with statutory requirements, comparative } \\
\text { advantage and MDB policy priorities }\end{array}$ \\
\hline & & Effectiveness & Solutions in line with development needs \\
\hline \multirow{6}{*}{$\begin{array}{l}\text { IDB's Development } \\
\text { Effectiveness Framework [14] }\end{array}$} & \multirow[b]{2}{*}{2008} & \multirow[b]{2}{*}{ Effectiveness } & Clear and verifiable objectives \\
\hline & & & $\begin{array}{c}\text { Establishment of monitoring and evaluation } \\
\text { mechanisms }\end{array}$ \\
\hline & & \multirow{2}{*}{ Efficiency } & Cost/benefit analysis \\
\hline & & & Cost-effective interventions \\
\hline & & \multirow{2}{*}{ Risk and Sustainability } & Appropriate risk management \\
\hline & & & Creation of favorable conditions to maintain results \\
\hline & & Additionality to Ins & tional Development, environmental and social \\
\hline \multirow{2}{*}{ Gasché, J. \& Vela, N. [15] } & \multirow{2}{*}{2012} & \multicolumn{2}{|c|}{ Identification of beneficiaries' needs } \\
\hline & & \multicolumn{2}{|c|}{ Identification of beneficiary priorities } \\
\hline \multirow{6}{*}{ Muro, J. [16] } & \multirow{6}{*}{2012} & Exogenous requirements & $\begin{array}{l}\text { Preconditions to be met or actions that must } \\
\text { necessarily be carried out by the beneficiary regardless } \\
\text { of the activity. }\end{array}$ \\
\hline & & Internal factors & Correct identification of priorities \\
\hline & & \multicolumn{2}{|r|}{ Risk management } \\
\hline & & \multicolumn{2}{|c|}{ Adaptation to local conditions } \\
\hline & & \multicolumn{2}{|r|}{ Project Quality Assurance } \\
\hline & & \multicolumn{2}{|c|}{ Cohesion structure between the team of experts and the beneficiary team } \\
\hline $\begin{array}{l}\text { Lavagnon A. Diallo A., Diallo A. } \\
\text { y Thuillier D. [12,17] }\end{array}$ & 2012 & \multicolumn{2}{|c|}{ Monitoring, coordination, design, training, and institutional environment. } \\
\hline \multirow{5}{*}{ Mohareb, M. [18] } & \multirow{5}{*}{2017} & Internal factors & Adequate needs assessment \\
\hline & & External factors & Clear understanding of the project context \\
\hline & & \multirow{3}{*}{ Cooperation factors } & Effective consultation with all stakeholders \\
\hline & & & Monitoring \\
\hline & & & Evaluation \\
\hline
\end{tabular}

Some authors link the success of a development cooperation project to the proper operational management of the project, while others link it to the evaluation of environmental conditions, effectiveness, and efficiency, while for others success depends on quality, risk management, and sustainability. Thus, the critical factors defined and evaluated in the research were: effectiveness, understood as the result of efficacy and efficiency; relevance, understood as the extent to which the project adapts to the priorities and policies of the participating roles; competencies and motivation; sustainability; risk management; and additionality.

- Effectiveness factor. Effectiveness is understood as the ratio of Outputs Produced to Expected Outputs (SO/SE); efficiency as the ratio of Outputs Produced to Outputs Used (SO/IU) [19]. The result of both is known as effectiveness, whose measurement is calculated by the degree of fulfillment of the objectives in the optimum possible time considering their relative importance and recognizing the changes introduced in the project since its approval. Its components are effectiveness, efficiency, and impact [5].

Efficacy: Level of the fulfillment of objectives obtained about those foreseen. Its subcomponents are: 
- Definition of clear and verifiable objectives;

- $\quad$ Adequate evaluation of the needs of the beneficiary population;

- Technical and operational feasibility.

Efficiency: Level of compliance with the objectives while making good use of available resources (manpower, time, and materials and supplies). Efficiency, in addition to the good use of resources, maintains good quality management of the project. Its subcomponents are:

- Level of the fulfillment of objectives with adequate use of resources;

- $\quad$ Permanent quality management.

Impact: This factor is understood as the valuation of project results perceived by the beneficiary population. Its subcomponents are:

- Adequate contribution of the products to the fulfillment of the specific and main objectives;

- $\quad$ Degree of the fulfillment of the beneficiary population's expectations.

- Relevance Factor. This is measured according to how the project is adapted to the priorities and policies of the beneficiary population, the consultant or the executing unit (or both). Its components are:

- Strategic congruence of the project's objectives with the needs of the beneficiaries, development, as well as the country's policies;

- Establishment of strategic alliances among stakeholders.

- Competency and motivation factors. Its components are:

- $\quad$ Structure of cohesion between the team of experts and the beneficiary team;

- $\quad$ Time to support the project;

- Commitment;

- Internal interaction between roles;

- Effective communication with all stakeholders;

- Ability to adapt to local conditions;

- $\quad$ Rotational leadership skills;

- Years of experience participating in development cooperation projects;

- $\quad$ Acquired technical knowledge;

- Organizational skills;

- $\quad$ Experience in project management;

- $\quad$ Experience in management of development cooperation projects.

- Sustainability Factor. When the needs of the present are met without compromising the needs of future generations. Its components are:

- Social Contribution: By improving the quality of life of the target population;

- Environmental contribution;

- Economic contribution.

- $\quad$ Risk management Factor.

- $\quad$ Risk management and appropriate mitigation.

- Additionality Factor.

- $\quad$ Training and advice as well as technical support to the beneficiary population;

- Establishment of monitoring and evaluation mechanisms;

- Creation of favorable conditions for sustaining results.

\subsection{Hypotheses and Specific Objectives}

As in all research, through the literature review, the following hypotheses (Hi) were proposed, which were aligned with the objectives (Oi).

Hypothesis 1 (H1). The analysis of the Development Effectiveness Matrix should be deepened. This matrix is used in the IDB Group's current methodology to evaluate the performance of its financing operations [4]. The model to be proposed will be obtained through an evaluation of 
the proposed success factors and the order of their relevance according to the perception of the professionals who will participate in the research.

O1. Analyze the relationship and causality of factors. Based on the first hypothesis, the first objective was defined as an analysis of the relationship and causality of factors that influence the success of projects.

Hypothesis 2 (H2). Roles must comply with a high level of participation. The participation of the different roles that are part of the stakeholder matrix will be evaluated.

O2: Identify an adequate relationship between the competencies of each role.

O3: Benchmarking stakeholder participation.

Based on the second hypothesis, the aforementioned two objectives were proposed, which were to identify an adequate relationship of the competencies that the roles should acquire and to carry out a comparative evaluation of what is expected from the participation of the actors involved in a project.

Hypothesis 3 (H3). Agile methodology is the most appropriate methodology. According to the IDB's Practical Guide, the agile methodology constitutes a leap into the future for the management of development projects, since these are in a complex, changing, and highly uncertain environment [20].

O4: Identify the most appropriate project management methodology. Based on the third hypothesis, the last objective was defined as the identification of the project management methodology that is best applied in development cooperation projects.

\section{Methodology}

The main objective of the research was to carry out a comparative qualitative analysis of factors that influence development cooperation projects to obtain a model that relates components, factors that influence the success of projects, and the roles that make up the stakeholder matrix, which can be applied in the annual review carried out by the IDB's Office of Evaluation and Oversight to strengthen the monitoring and evaluation carried out in the different phases of project financing. The research proposal was mainly based on the analysis of the roles involved through a form containing Likert scale questions to evaluate the levels of participation and the perception of critical factors. The process followed is summarized in the diagram in Figure 1. As for the documentary research, articles were reviewed, mostly from the Web of Science related to research on multilateral projects and the factors influencing their success, as well as IDB reports.

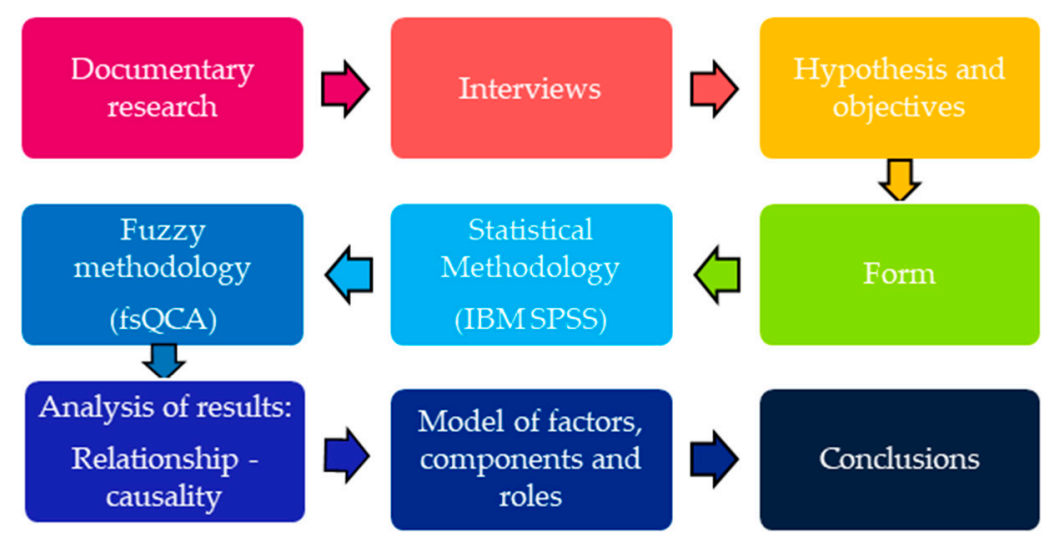

Figure 1. Research process diagram.

Meetings with specialists such as Margarita Libby, representing the IDB, and Fernando Bejarano, who is an expert in foreign trade and development cooperation project manage- 
ment, have also been held. Both interviews helped to understand how cooperation projects are managed according to the perspective of each of the roles and provided support with the revision of the form before its dissemination; however, not without first defining the hypotheses and objectives previously explained.

For the quantitative analysis of the research, the IBM SPSS software, an acronym for Statistical Package for the Social Sciences, was used and the FsQCA 3.0 software, acronym of Fuzzy set Qualitative Comparative Analysis, was also used for the application of the fuzzy methodology to perform an analysis of causal configurations. After performing the statistical and fuzzy analysis, an analysis of results was performed, where a model of factors, components and roles was also defined; finally, conclusions were drawn.

\subsection{IBM SPSS}

Thanks to the IBM SPSS software, the quantitative analysis of the research was carried out using descriptive statistics through the study of means, median and standard deviation in order to be able to interpret the data obtained in the research quantitatively in the evaluation of the profile characteristics that the roles must have in order for a cooperation project to succeed $[5,21]$. The IBM SPPS offers a set of advanced statistical analysis tools for data processing, such as Linear regression model function, Pearson correlation analysis, model adjustment, and ANOVA. This program is often used to analyze complex statistical data in the social sciences. In addition, it provides researchers with tools that allow them to quickly consult data and formulate hypotheses, perform procedures to clarify relationships between variables, identify trends, and make predictions.

\subsection{FsQCA 3.0}

The fuzzy methodology is used in the research through the FsQCA 3.0 program since it uses combinatorial logic, set theory, and Boolean minimization to determine the combination of features necessary or sufficient to give a result or the output variable [22]. Charles Ragin has been the leading guide for his development of the software package as one of his contributions to sociology to bridge the gap between quantitative and qualitative methods [23].

\subsection{Form}

The form, designed in Google Forms with three sections, contained Likert-scale questions to assess levels of participation and perceptions of critical factors. The first section consisted of five questions to extract demographic information: age, nationality, gender, education level, and occupation of the participants. The second section consisted of six questions asking for general information about the projects in which the participant participated, such as years of experience, the country where the project(s) was implemented, sector, year of participation, duration of the project; and the last section regarded the role that the participant has played in the development cooperation project(s).

This last section also had three parts. The first part consisted of evaluating, according to a Likert scale, the degree of relevance of the profile that the roles should have to ensure that a project is successful. The second part consisted of evaluating the order of the success factors and their components that constitute all the participatory roles. Likewise, the IDB's presence in the execution of the project was evaluated in terms of support, followup, and evaluation. In the last part, the most appropriate methodology to be applied in development cooperation projects was evaluated. Due to knowledge issues, this question was asked to all roles, except to the beneficiary population.

\subsection{Participants Description}

In terms of demographic data, Figure 2 shows it should be noted that the 48 respondents were professionals over $25,68 \%$ were male and of 12 different nationalities, with more than $50 \%$ of the participants being Peruvian. In addition, the participants have experience participating in this type of project for more than 15 years; in sum, there was participation 
in 132 projects that belonged to at least one sector of the IDB developed between 2000 and 2020, with an average duration between 3 and 6 years. The roles they occupied and that are part of the stakeholder matrix are as follows: $26 \%$ occupied the role of Executing Unit (EU); $23 \%$ belonged to a consultancy or were IDB staff that occupied the role of consultant (C); $21 \%$ were part of the IDB staff that evaluates and follows up the projects (IDB); $17 \%$ were part of an Executing Agency, which are usually ministries; and the rest were part of the beneficiary population (BP).

About the 48 participants:

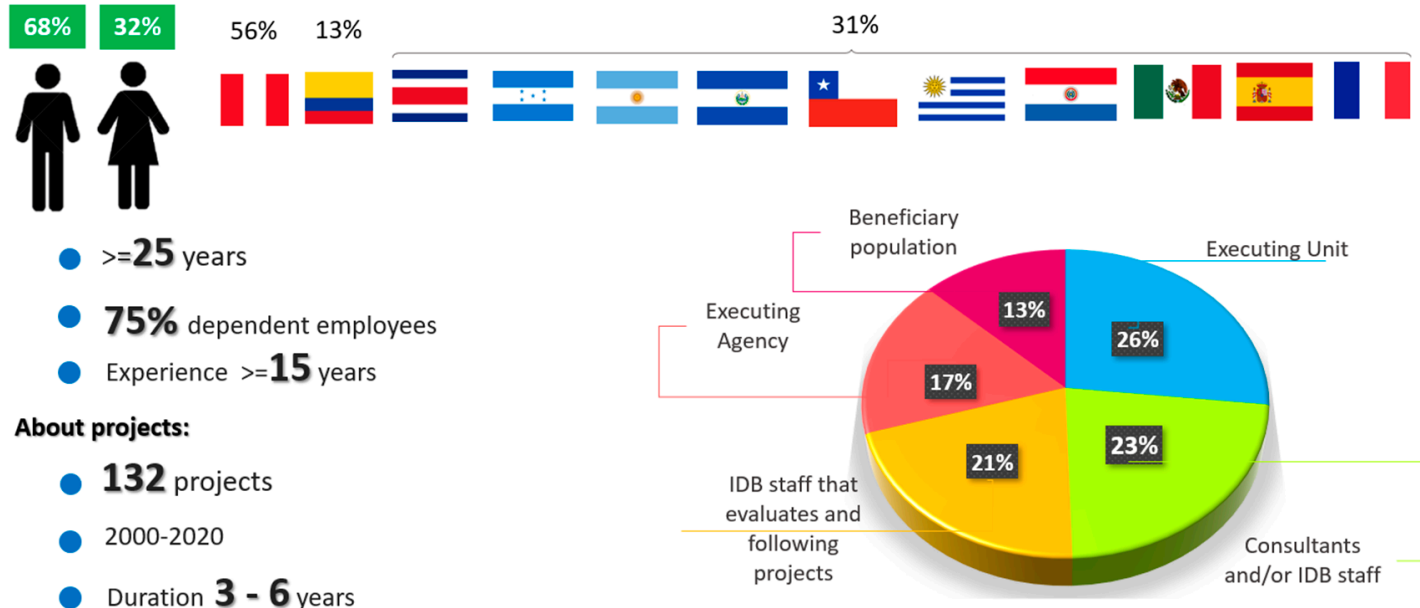

Figure 2. Participants.

\section{Results}

\subsection{Statistical Analysis: Effectiveness and Success}

The three variables evaluated in the form were effectiveness, relevance and sustainability, and risk management, whose values were obtained by means of a weighted average from the scores obtained from the components with the weight calculated by the mean of each component. The data entered into the IBM SPSS program are shown in Appendix A. The following hypothesis was defined to proceed with the correlation analysis and test hypothesis 1:

Hypothesis $4 \mathbf{( H 4 ) . ~ T h e ~ f a c t o r s ~ e f f e c t i v e n e s s , ~ r e l e v a n c e ~ a n d ~ s u s t a i n a b i l i t y , ~ a n d ~ r i s k ~ m a n a g e m e n t ~}$ influence the success of development cooperation projects.

Dependent Variable: (1) SUCCESS, Success of the project.

Independent Variables: (1) EFT, Effectiveness, (2) PTN, Relevance and (3) SGR, Sustainability and Risk Management.

\subsubsection{Linear Regression Model}

Table 3 shows the EFT variable (X1) should remain in the model, since $\beta 1$ is different from 0 , while the PTN and SGR variables (X2 and $X 3$, respectively) result in greater than 0.05 , with $\beta 2$ and $\beta 3$ equal to 0 , making them non-significant for the linear regression model.

Table 4 shows since the effectiveness variable had to remain in the linear regression model because it was a significant variable, the multiple linear regression model is as follows:

$$
\hat{y}=0.337+1.056 X 1
$$


Table 3. Coefficients Analysis of EFT, PTN, and SGR variables. Source: adapted from [4].

\begin{tabular}{ccccc}
\hline \multirow{2}{*}{ Model } & \multicolumn{2}{c}{ Non-Standardized Coefficients } & & \\
\cline { 2 - 3 } & B & Sig. & \\
\hline (Constant) & 0.584 & 0.407 & 0.159 & \\
EFT & 1.190 & 0.171 & 0.000 & $\leq 0.05 ;$ Ho: $\beta 1=0(\mathrm{f})$ \\
PTN & -0.128 & 0.367 & 0.729 & $\geq 0.05 ;$ Ho: $\beta 2=0(\mathrm{v})$ \\
SGR & -0.157 & 0.324 & 0.630 & $\leq 0.05 ;$ Ho: $\beta 3=0(\mathrm{v})$ \\
\hline
\end{tabular}

Table 4. Coefficients Analysis of EFT, PTN, and SGR variables. Source: adapted from [4].

\begin{tabular}{|c|c|c|c|c|c|c|c|}
\hline \multirow{2}{*}{ Model } & \multicolumn{2}{|c|}{ Non-Standardized Coefficients } & \multirow{2}{*}{ Sig. } & \multirow{2}{*}{$\mathbf{t}$} & \multirow{2}{*}{ Sig. } & \multicolumn{2}{|c|}{ Collinearity Statistics } \\
\hline & B & Standard Error & & & & Tolerance & FIV \\
\hline (Constant) & 0.337 & 0.295 & & 1.144 & 0.259 & & \\
\hline EFT & 1.056 & 0.089 & 0.868 & 11.829 & 0.000 & 1.000 & 1.000 \\
\hline
\end{tabular}

\subsubsection{Pearson Correlation Analysis}

To study the relationship between the variables, the Pearson correlation coefficient was used, which indicates the degree of association between them. This coefficient, closer to the value of unity, means that the variables are more closely related, and as long as the significance value is less than $5 \%$, it is generally accepted in social research [24]. Table 5 shows that the coefficient of the variable is less than 0.9 , which is a strong correlation, so it is considered statistically significant.

Table 5. Correlation. Source: adapted from [4].

\begin{tabular}{cccc}
\hline & & SUCCESS & EFT \\
\hline \multirow{2}{*}{ Pearson correlation } & SUCCESS & 1.000 & 0.868 \\
& EFT & 0.868 & 1.000 \\
\hline \multirow{2}{*}{ Sig. (unilateral) } & SUCCESS & & 0.000 \\
& EFT & 0.000 & \\
\hline \multirow{2}{*}{$\mathrm{N}$} & SUCCESS & 48 & 48 \\
& EFT & 48 & 48 \\
\hline
\end{tabular}

\subsubsection{Model Adjustment}

Table 6 shows that the multiple correlation coefficient between the predictors and the criterion variable is 0.868 , which indicates a strong and significant correlation since the relationship between the success variable increases due to the effectiveness variable, while the R-squared determines that $75.3 \%$ of the variability of the success variable is explained by the regression model formed by the predictor variable. Furthermore, if the model were derived from the entire population instead of a sample, as is the case in the research, it would account for $0.6 \%$ variance in the result. This is due to the minimal difference between the adjusted R-squared and the R-squared values.

Table 6. Model Summary. Source: adapted from [4].

\begin{tabular}{ccccccccccc}
\hline \multirow{2}{*}{$\mathbf{R}$} & \multirow{2}{*}{ R2 Value } & $\begin{array}{c}\text { R2 Value } \\
\text { Corrected }\end{array}$ & $\begin{array}{c}\text { Standard } \\
\text { Error }\end{array}$ & $\begin{array}{c}\text { Change } \\
\text { in R2 }\end{array}$ & $\begin{array}{c}\text { Change } \\
\text { in F }\end{array}$ & g11 & g12 & $\begin{array}{c}\text { Sig. } \\
\text { Change F }\end{array}$ & Durbin-Watson \\
\hline 0.868 & 0.753 & 0.747 & 0.5759 & 0.753 & 139.918 & 1 & 46 & 0.000 & 2.49 \\
\hline
\end{tabular}




\subsubsection{Anova}

H1: $p=0$ (No linear correlation).

Ho: $p \neq 0$ (There is a linear correlation between success and effectiveness).

Decision rule: Reject Ho if the value of $p \leq \alpha$.

Table 7 shows there is sufficient sample evidence to test the multiple linear correlations between the Efficacy factor and the success factor because the Ho is rejected as true.

Table 7. Anova. Source: adapted from [4].

\begin{tabular}{cccccc}
\hline Model & Squares Sum & Fg & Root Mean Square & F & Sig. \\
\hline Regression & 46.407 & 1 & 46.407 & 139.918 & 0.000 \\
Residual & 15.257 & 46 & 0.332 & & \\
Total & 61.664 & 47 & & & \\
\hline$p-$ value $=0.000$ & & & & & \\
\hline
\end{tabular}

\subsection{Fuzzy Set Analysis: Sustainability and Risk Management}

\subsubsection{Variable Selection}

The factors evaluated were effectiveness (EFT), relevance (PTN), and sustainability and risk management (SGR). The analysis of these with the FsQCA program was based on the scores of each of the 48 participants or cases concerning the assessment made for each factor influencing the success of the development cooperation projects and their components. In sum, the participants cooperated in a total of 132 projects, whose information has not been provided in the present research, a variability of scores is shown due to the difference of opinions and perspectives that the participants have regarding their participation experience; however, this variation is resolved in the calibration for the treatment of the same. For each factor, several components related to the assessment of its influence have been defined. The number of these components constitutes the input variables or conditions, while the output or outcome variables will be the success factors. The values of the components, as well as the results for each of the research participants, are shown in Appendix B.

\subsubsection{Variable Preparation}

The FsQCA 3.0 (Fuzzy set Qualitative Comparative Analysis) software was used to apply the fuzzy methodology since it uses (fuzzy) set theory and Boolean algebra to analyze the extent to which certain factors or combinations of factors are present or absent when a phenomenon of interest occurs or not [25]. This methodology performs a systematic cross-search analysis that models a relationship between variables related to the membership of a set and configuration of identities that reflect a sufficient condition for an outcome of interest. The factors that are considered to be causes of a phenomenon are called "conditions", while the phenomenon itself is called "outcome"; thus, once the sample of 48 people (or cases) is available, with the 12 input variables (the characteristics of the profile that professionals from consulting firms or the IDB should have) and the 4 output variables (the factors that influence the success of development cooperation projects), they are calibrated to analyze the data in the fsQCA 3.0 program. The calibration allows to evaluate the established scores in relation to external norms and existing theory. Boolean algebra facilitates the transformation of the original scale values into values of the fuzzy sets for the antecedent (independent variable) and outcome (dependent variable) conditions. Calibration makes fuzzy sets superior to conventional measures, as they offer a middle way between quantitative and qualitative measures [26].

Direct calibration was used for the investigation, as it uses the full membership threshold, the not full membership threshold, and the crossover point, which is the value of the interval scale variable at which there is maximum ambiguity about whether a case is more inside or more outside the target set. These three crossover points are used to transform the original ratio or interval scale values into fuzzy membership scores using transformations based on the logarithmic probabilities of full membership. Calibration 
determines the degree of membership of the cases in each of the sets, with scores ranging from 0 to 1 . In the program the operation is performed through the calibrate function $(\mathrm{x} 1, \mathrm{n} 1, \mathrm{n} 2, \mathrm{n} 3)$, where $\mathrm{x} 1$ represents the name of a ratio or interval scale variable already existing in the file, $\mathrm{n} 1$ corresponds to the threshold of full membership in the target set (0.95), $\mathrm{n} 2$ corresponds to the crossover point (0.5) in the target set and $\mathrm{n} 3$ corresponds to the threshold of non-membership in the target set (0.05) [23]. For these reasons, it was decided to work with the maximum, minimum and mean of the scores obtained. Thus, in Appendix $C$ it can be seen what the interpretation of these calibrations would be.

\subsubsection{Analysis of the Necessary Conditions}

As explained in the fsQCA software User's Guide, the main difference between a necessary and sufficient condition is that a necessary condition must be present for an outcome to occur, whereas a sufficient condition by itself can produce a given outcome [23]; however, neither necessity nor sufficiency exists independently of the theories proposing the conditions; rather, they are often considered together because all combinations of the two are meaningful. There are four categories of conditions formed from the crosstabulation of presence or absence of sufficiency versus presence or absence of necessity.

A condition is necessary and sufficient if it is the only condition that produces an outcome, and it occurs because of a combination of causes.

A condition is necessary, but not sufficient, if it can produce a result in combination with other causes and appears in all those combinations. Finally, a condition is neither necessary nor sufficient if it appears in only a subset of the combinations of conditions that produce an outcome.

For the research, since the fuzzy methodology results in a logical statement describing combinations of conditions that are sufficient for the outcome, the listed combinations may not explain all cases of the outcome. Next, both the necessity and sufficiency of individual conditions were examined before analyzing sufficient combinations of conditions.

That said, the values obtained for the outcome SUCCESS and its negated version ( SUCCESS) are analyzed, while the conditions were the factors (EFT, PTN, SGR) and their negated versions $(\sim \mathrm{EFT}, \sim \mathrm{PTN}, \sim \mathrm{SGR})$, which represent the absence of the conditions or the outcome. According to Ragin [26], a condition is necessary when it has a consistency index value greater than 0.9. From Table 8, which shows the summary of the results obtained for the necessary conditions, it can be seen that for a development cooperation project to be very successful, according to the Necessary conditions, it needs to consider mainly the effectiveness and sustainability factors. This can be interpreted that as long as the objectives are met with those foreseen, making good use of the resources, meeting the expectations of the population, presenting a good technical and operational feasibility that is controlled with adequate risk management, and is sustainable over time, generating a positive impact on the population in the short, medium, and long term, contributing to society, the environment, and the economy of the region, the project can be considered successful. Similar results were obtained in previous studies such as Rodríguez-Rivero et al. 2020, analyzing development projects in Colombia [27].

Table 8. Necessary conditions for results. Source: adapted from [4].

\begin{tabular}{ccccc}
\hline \multirow{2}{*}{ Condition } & \multicolumn{2}{c}{ SUCCESS } & \multicolumn{2}{c}{$\sim$ SUCCESS } \\
\cline { 2 - 5 } & Consistency & Coverage & Consistency & Coverage \\
\hline EFT & $\mathbf{0 . 9 5 0 6 4 6}$ & 0.920364 & 0.565526 & 0.996587 \\
$\sim$ EFT & 0.896475 & 0.557528 & $\mathbf{0 . 9 5 4 8 0 9}$ & 0.972387 \\
PTN & 0.899530 & 0.836155 & 0.590381 & 0.998908 \\
$\sim$ PTN & 0.888825 & 0.572583 & $\mathbf{0 . 9 0 3 1 6 3}$ & 0.942405 \\
SGR & $\mathbf{0 . 9 5 3 5 8 4}$ & 0.885434 & 0.591026 & 0.998909 \\
$\sim$ SGR & 0.898825 & 0.572969 & $\mathbf{0 . 9 3 2 2 1 4}$ & 0.973374 \\
\hline
\end{tabular}


On the other hand, when success is absent ( Success), the most influential condition is the absence of effectiveness. This is interpreted as meaning that a project will not be successful if there is no good control of this factor in the management of cooperation projects. Similarly, the factors of relevance and sustainability must be considered since their absence would cause the failure of the project.

\subsubsection{Analysis of the Necessary Conditions}

To continue with the data processing, the data matrix was transformed into a truth table. The truth table algorithm asks to indicate the result through the settings option and the conditions through the add option to add the conditions. These conditions will be used to analyze the conditions leading to the presence of the result and to analyze the absence of the result. To do this, the negation of the result must also be set with the "Set negated" option. The program allowed to show the cases of each row that represent the scores of the participants in the truth table, so the option to activate the cases in the output was activated through the option "Show solution cases" in the output. As mentioned, the purpose of the methodology is to identify the sufficient configuration for the truth table algorithm to identify enough cases to achieve the result. The first outcome defined is SUCCESS and the causal conditions EFT, PTN, and SGR.

Once the result has been archived, the conditions and cases of the model and the truth table of the Efficiency factor, have been indicated. The conditions in the truth table are described in terms of zeros, which indicate absence, and ones, which indicate presence. Therefore, although the data matrix contains fuzzy data, the truth table shows only zeros and ones.

In addition, one can see that the program has distinguished between all possible configurations in the rows, which is the first step in obtaining the truth table. The column "Cases" shows the number of cases in each row of the truth table and in brackets the cumulative percentage of each row. By pressing the buttons, it was possible to observe the cases that were assigned to the rows, representing the participants. Then, the value of the result of each row was determined according to its gross consistency in order to finish with the last part of the elaboration of the truth table and perform the logical minimization process. To determine which configurations or rows of the truth table are sufficient for the result, the column with the results in the table was defined. It is worth noting that the consistencies must be at least 0.75 for crisp sets and at least 0.8 for fuzzy sets to be considered a consistent and sufficient configuration for the result.

From the truth table, which presents $2 \mathrm{k}$ rows, with $\mathrm{k}$ being the number of causal conditions or independent variables, all possible combinations of causal conditions were reflected by presenting ones and zeros. These numbers represent the total membership and the null membership of each condition, respectively. For each row of the Truth Table, a value is created for each of the following variables: cases, raw consist, PRI consist, and SYM consist.

- Cases indicates the number of cases that show the combination of conditions;

- Raw consist presents the consistency or proportion of cases in each row of the truth table that show the result;

- $\quad$ PRI consist is an alternative measure of consistency developed for fuzzy sets based on a quasi-proportional reduction of the error estimate;

- SYM consist is an alternative measure of consistency for fuzzy sets based on a symmetric version of PRI consistency.

In the research, tests were carried out until the conditions of the sufficiency of coverage and consistency of the solution were at least 0.8 . This means a good representativeness according to Ragin (2008); however, there were also cases in which it was decided to accept a solution with average representativeness so that the values of own and unique coverage were acceptable, since their combinations would represent the best option within the valid working margins to obtain a reliable solution. This was the case for the efficacy, effectiveness, and relevance factors. On the other hand, since the research does not 
have many cases, the frequency threshold equivalent to 1 , which represents the minimum number of times a configuration must occur before including it in the minimization process, was kept at one. To start the logical minimization process, the Standard Analysis option was used, which automatically performs the minimization, unlike the Specific Analysis. The research analyzed how the conditions should contribute to the occurrence of the result when they are present or absent. The Standard Analysis produced three different results: complex solutions; simplified solutions; and intermediate solutions:

- Complex solutions, although the most complete and detailed solution, are the most difficult to interpret and is not recommended, as they provides very little insight into the causal conditions [28];

- $\quad$ Simplified solutions opt for maximization. In the program, they are those assumptions whose combination of conditions is false, id est., there are no cases present in the result. The main conditions can be found in this solution;

- There are also intermediate solutions, which are solutions that combine the logic of the two previous ones, and it is specified that certain causal configurations not included in real cases determine the success of the project. In this solution, main and contributing conditions can be found.

The Quine-McCluskey algorithm is the one applied in the software. Given that the most recommended solution for research projects for presenting better consistency than the simplified and complex solutions, the intermediate solutions were used [29]; likewise, it was also chosen to use the simplified solutions because it corroborated the presence of the main conditions since the intermediate ones presented these and the contributory ones. The intermediate solution is constituted by the effective thresholds of frequency and consistency. In addition, the minimum formula is found with each term of the solution in a row of the table described with the Boolean operations of the asterisk; and the consistency and coverage specified for each term of the solution and the solution as a whole:

- Consistency evaluates the degree of closeness of a subset relationship, being analogous to a correlation. It also measures the proportion of cases consistent with the result;

- Coverage assesses the empirical relevance of a consistent subset, analogous to a coefficient of determination. This is based on a causal combination that covers or accounts for cases of an outcome that spans a large proportion to be empirically important $[30,31]$.

The analysis of the combination of sufficient conditions to identify the causes of the success factors was performed with the fsQCA software. In the research only the analysis of the factors effectiveness, relevance and sustainability, and risk management was performed since the other factors (motivation and additionality) were summarized as a single component in the questions of the form; however, the presence of these factors in a project is as relevant as the factors that were analyzed.

\section{Combination of Sufficient Conditions for the SUCCESS Factor Result}

Of all the combinations, the most representative is the one with the highest own coverage. This is because the own coverage considers its participation in other conditions, while the single coverage only takes into account the coverage of the own condition. It is due to the overlap of cases in the different combinations that the single coverage presents very small values [32,33]. Table 9 presents the results for the intermediate and simplified solutions. With a minimum consistency threshold of 0.90 , it is observed that the intermediate solution has a coverage of 0.97 and a consistency of 0.82 , indicating that it has good representativeness of the conditions in the outcome variable, i.e., in the Efficiency Factor. Of the possible combinations, the configuration with the highest eigen-coverage of the table in the intermediate solution equals 0.954 and presents a very high consistency of 0.88 is $\sim$ PTN*SGR; as well as the other eigen-coverage of EFT ${ }^{*} \sim$ SGR and EFT $*$ PTN equals 0.494 and consistency of 0.92 . It can be inferred that the efficacy factor is more representative than the sustainability factor, and in two of them there is absence of significance. This means 
that the absence of relevance can be compensated by the effectiveness and sustainability factors. In the simplified solution, the EFT and SGR components are reaffirmed as important for the success of a project, presenting a solution with an own coverage equivalent to 0.97 and a unique coverage of 0.82 .

Table 9. Intermediate and simplified solution for the Success outcome. Source: adapted from [4].

\begin{tabular}{|c|c|c|c|c|}
\hline & Combination & Raw Coverage & Unique Coverage & Consistency \\
\hline \multirow{5}{*}{$\begin{array}{c}\text { Intermediate } \\
\text { Solutions }\end{array}$} & $\mathrm{PTN}^{*} \sim \mathrm{SGR}$ & 0.89953 & 0.00528777 & 0.836155 \\
\hline & PTN*SGR & 0.953584 & 0.000587523 & 0.885434 \\
\hline & $\mathrm{EFT}^{*} \sim \mathrm{SGR}$ & 0.949471 & 0 & 0.920273 \\
\hline & $\mathrm{EFT}^{*} \sim \mathrm{PTN}$ & 0.949471 & 0 & 0.920273 \\
\hline & \multicolumn{4}{|c|}{ Solution coverage: 0.97121 , Solution consistency: 0.823207.} \\
\hline \multirow{4}{*}{$\begin{array}{l}\text { Simplified } \\
\text { Solutions }\end{array}$} & EFT & 0.950646 & 0.00881314 & 0.920364 \\
\hline & PTN & 0.89953 & 0.00528777 & 0.836155 \\
\hline & SGR & 0.953584 & 0.000587523 & 0.885434 \\
\hline & \multicolumn{4}{|c|}{ Solution coverage: 0.97121 , Solution consistency: 0.823207.} \\
\hline
\end{tabular}

Thus, effectiveness and sustainability factors are considered as the main conditions; and absence of relevance $(\sim \mathrm{PTN})$ as a contributing condition.

Combination of Sufficient Conditions for the SUCCESS Factor Result

Table 10 shows the possible combinations of the intermediate solution. For this case, the simplified solution is not shown because the software failed to detect any row in the truth table that is accepted as sufficient for the result. With a minimum consistency of 0.8 , it was observed that the solution presents a high representativeness with a coverage of 0.95 and a consistency of 0.94 . It can be observed that the most representative and successful unique combination is $\sim$ SGR, which has a coverage of 0.93 and 0.97 , respectively. This means that, in the absence of good control over sustainability and risk management, the project will not be successful.

Table 10. Intermediate and simplified solution for the result $\sim$ SUCCESS Factor. Source: adapted from [4].

\begin{tabular}{cccc}
\hline $\begin{array}{c}\text { INTERMEDIATE Solution } \\
\text { Combinations }\end{array}$ & Raw Coverage & Unique Coverage & Consistency \\
\hline$\sim$ SGR & $\mathbf{0 . 9 3 2 2 1 4}$ & 0.0432537 & 0.973374 \\
$\sim$ PTN & $\mathbf{0 . 9 0 3 1 6 3}$ & 0.0142025 & 0.942405 \\
\hline
\end{tabular}

Solution coverage: 0.946417; Solution consistency: 0.940346 .

Thus, the absence of the sustainability and risk management ( SGR) factor can be considered as the main component. There are no contributing conditions.

\section{Discussions}

\subsection{Components, Factors and Roles}

Figure 3 shows the summary of the necessary and sufficient conditions obtained from the data processing for each of the components of the solutions and combinations, as well as their respective consistencies and coverages.

The above table shows that the sustainability and risk management factor is the main factor that causes the success or failure of development cooperation projects. This causal relationship and its components are shown again in Figure 4. 


\begin{tabular}{|c|c|c|c|c|c|c|c|c|c|}
\hline Solutions & \multicolumn{2}{|c|}{ Combinations } & $\begin{array}{c}\text { Raw } \\
\text { Coverage }\end{array}$ & $\begin{array}{c}\text { Unique } \\
\text { Coverage }\end{array}$ & Consistency & EFT & PTN & SG & \\
\hline \multirow{3}{*}{ SUCCESS } & \multicolumn{2}{|c|}{$\sim$ PTN*SGR } & 0.9536 & 0.0006 & 0.8854 & & & & \\
\hline & \multicolumn{2}{|c|}{$\mathrm{EFT}^{*} \sim \mathrm{SGR}$} & 0.9495 & 0.0000 & 0.9203 & & & & \\
\hline & \multicolumn{2}{|c|}{$\mathrm{EFT}^{*} \sim \mathrm{PTN}$} & 0.9495 & 0.0000 & 0.9203 & & & & \\
\hline \multirow{2}{*}{ SUCCESS } & \multicolumn{2}{|c|}{$\sim \mathrm{SGR}$} & 0.9322 & 0.0433 & 0.9734 & & & & 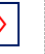 \\
\hline & \multicolumn{2}{|c|}{$\sim \mathrm{PTN}$} & 0.9032 & 0.0142 & 0.9424 & & $\Delta$ & & \\
\hline \multicolumn{2}{|c|}{ Necessary condition present } & \multicolumn{3}{|c|}{ Principal sufficient condition present } & \begin{tabular}{l|l} 
& Sufficient cc
\end{tabular} & & tion pre & & $>$ \\
\hline \multicolumn{2}{|c|}{ Necessary condition absent } & $\square$ Suffi & ient main conditi & on absent & Sufficient con & is & contribu & & $\Delta$ \\
\hline
\end{tabular}

Figure 3. Intermediate and simplified solution for the result $\sim$ SUCCESS Factor. Source: adapted from [4].

\begin{tabular}{l}
\multicolumn{1}{|c|}{ SUSTAINABILITY } \\
Improvement quality life of the beneficiary population \\
Environmental contribution \\
Economic contribution \\
\hline \multicolumn{1}{|c|}{ RISKMANAGEMENT } \\
Adequaterisk managemente and mitigation
\end{tabular}

Figure 4. Significant relationship between Success and sustainability and risk management factors.

For the purposes of this research, sustainability and risk management are factors that, although closely related in project management, diverge in their concept. Sustainability is understood as the balance between the environmental, social, and economic spheres. In other words, the active participation of all the roles involved must be ensured for its continuity without compromising future generations, contributing to development, and seeking homogeneity and coherence between economic growth and respect for the environment. Risk management was included in this research because it was identified that many times, a lot of time and effort is invested in solving problems in projects instead of preventing, mitigating, and anticipating them in a context of uncertainty.

Figure 5 summarizes the causal relationships of the factors analyzed and the data processing analysis performed in IBM SPSS and fsQCA software. From the analysis of the relationship variables, it turned out that there is a strong and significant correlation between the effectiveness and success of development cooperation projects. This explains why the IDB's RVO uses the Development Effectiveness Framework, a framework that promotes good practices for project design, implementation, and evaluation. This result also coincides with Diallo and Thuillier, who related the components of effectiveness (effectiveness and efficiency) as one of the dimensions to define the success of a project. Both criteria are guiding measures of the degree of performance of the executing team, time management, costs, as well as the level of achievement of objectives [34].

Although a very close relationship was found between effectiveness and the success of a project, after the literature review it was understood that this component is not only the result of efficacy and efficiency, but also the impact generated by the project in the locality where it is developed, measured through the degree of fulfillment of the beneficiary population's expectations. 


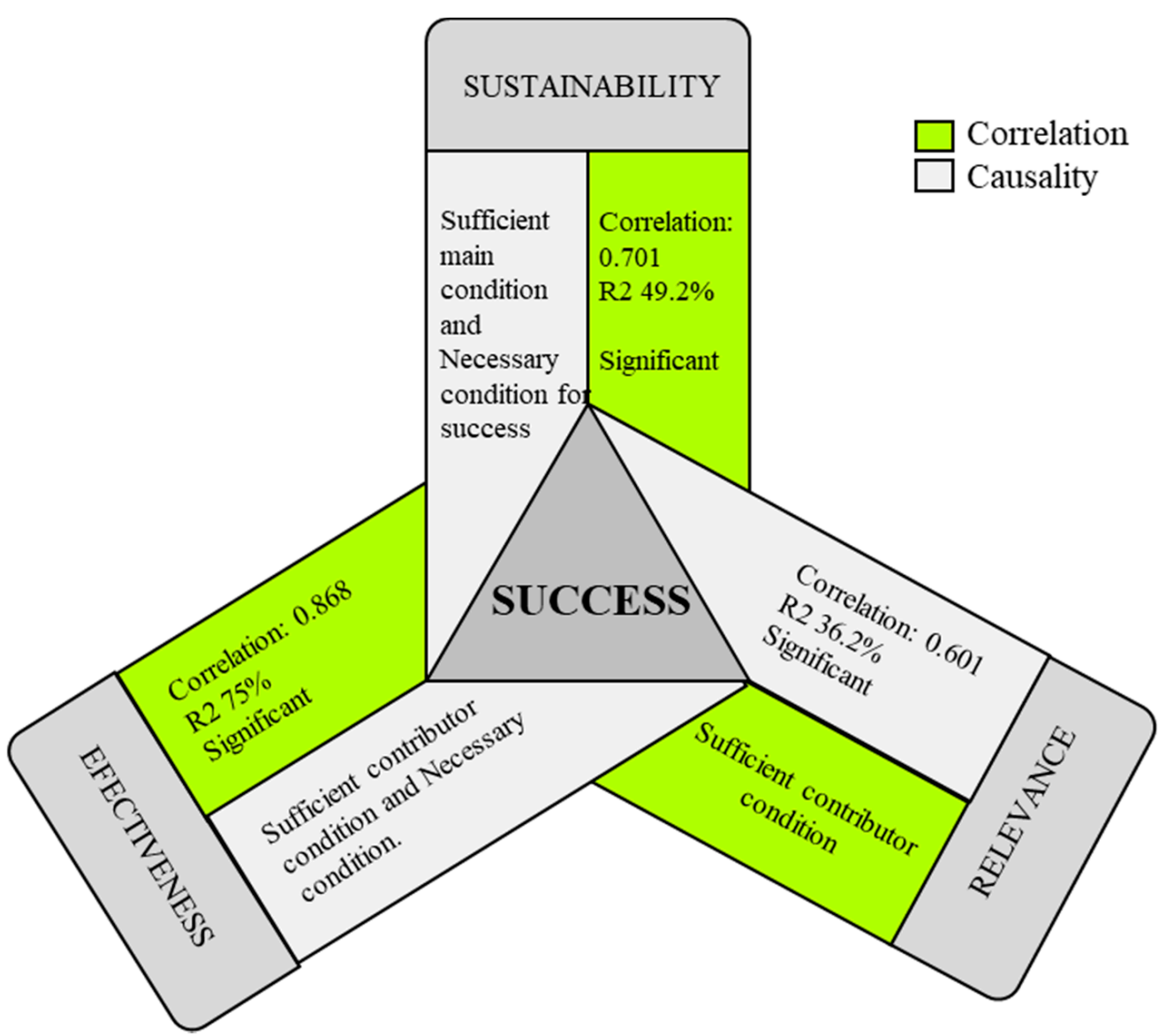

Figure 5. Comparison of relationship versus causality of the factors effectiveness, sustainability, and relevance with the variable Success. Source: adapted from [4].

From the assertion that the success of a project is mainly due to good sustainability and risk management in the project, since it has been shown that they represent a necessary and sufficient condition. It should be remembered that a condition is necessary and sufficient when it is the only one that produces a result. Effectiveness, for its part, turned out to be a sufficient contributing condition because it is capable of producing the result, but not the only cause with this capacity, and necessary, although less so than sustainability because it needs other conditions to produce success. Finally, in the case of relevance, it is concluded that it influences the success of the cooperation project. It turned out to be a sufficient condition, but not as much as effectiveness.

Table 11 presents the relationships between the components, factors, and roles involved in a development cooperation project for it to be successful. This contribution is mainly for the Development Effectiveness Framework, which, as mentioned in hypothesis 1, needed to improve the analysis of the factors: number one represents a very necessary condition that the role must fulfill based on the perceived expectation of the other roles; number two is necessary; number three means partially necessary; number four is neither necessary nor unnecessary; and number five is unnecessary. 
Table 11. Model of factors, components, and roles in relation to project success. Source: adapted from [4].

\begin{tabular}{|c|c|c|c|c|c|c|c|}
\hline Priority Order & Factors & \multicolumn{2}{|l|}{ Components } & $\mathrm{C}$ & EU & IDB & BP \\
\hline \multirow{3}{*}{$1^{\circ}$} & \multirow{3}{*}{ Sustainability } & \multirow{3}{*}{\multicolumn{2}{|c|}{$\begin{array}{l}\text { Improving the quality of life of the target population. } \\
\text { Environmental } \\
\text { Economical }\end{array}$}} & 1 & 1 & 1 & 5 \\
\hline & & & & 1 & 1 & 1 & 4 \\
\hline & & & & 2 & 2 & 1 & 4 \\
\hline $2^{\circ}$ & $\begin{array}{l}\text { Risk } \\
\text { management }\end{array}$ & \multicolumn{2}{|c|}{ Risk management and appropriate mitigation } & 1 & 1 & 1 & 4 \\
\hline \multirow{7}{*}{$3^{\circ}$} & \multirow{7}{*}{ Effectiveness } & \multirow{3}{*}{$\begin{array}{l}\text { Level of attainment of objectives } \\
\text { achieved in relation to those } \\
\text { planned }\end{array}$} & $\begin{array}{c}\text { Definition of clear and verifiable } \\
\text { objectives }\end{array}$ & 1 & 1 & 1 & 4 \\
\hline & & & $\begin{array}{l}\text { Adequate assessment of the needs } \\
\text { of the beneficiary population. }\end{array}$ & 2 & 1 & 1 & 4 \\
\hline & & & $\begin{array}{c}\text { Technical and operational } \\
\text { feasibility }\end{array}$ & 1 & 1 & 1 & 5 \\
\hline & & Level of achievement of objecti & s with adequate use of resources & 1 & 2 & 2 & 3 \\
\hline & & Ongoing qual & y management. & 1 & 2 & 2 & 5 \\
\hline & & $\begin{array}{r}\text { Adequate contribution of the proc } \\
\text { and mair }\end{array}$ & $\begin{array}{l}\text { icts to the fulfillment of the specific } \\
\text { objectives. }\end{array}$ & 1 & 2 & 2 & 5 \\
\hline & & $\begin{array}{r}\text { The degree to which the expectatio } \\
\text { bee }\end{array}$ & $\begin{array}{l}\text { s of the beneficiary population have } \\
\text { met }\end{array}$ & 1 & 1 & 1 & 5 \\
\hline \multirow[t]{2}{*}{$4^{\circ}$} & \multirow[t]{2}{*}{ Relevance } & $\begin{array}{r}\text { Strategic alignment of project objectives with the } \\
\text { and country poli }\end{array}$ & $\begin{array}{l}\text { needs of beneficiaries, development } \\
\text { ies. }\end{array}$ & 2 & 1 & 1 & 4 \\
\hline & & Establishment of strategic allianc & s with stakeholders & 2 & 2 & 1 & 5 \\
\hline \multirow{18}{*}{$5^{\circ}$} & \multirow{18}{*}{$\begin{array}{l}\text { Skills and } \\
\text { motivation }\end{array}$} & Cohesion structure between the team of ex & erts and the beneficiary team & 1 & 2 & 1 & 4 \\
\hline & & Time available to suppo & the project & 1 & 1 & 2 & 3 \\
\hline & & Project commitn & ent & 1 & 1 & 1 & 1 \\
\hline & & Internal role inter & ction & 1 & 1 & 1 & 1 \\
\hline & & Effective communication wit & all stakeholders & 1 & 1 & 1 & 2 \\
\hline & & Ability to adapt to local & conditions & 2 & 2 & 3 & 1 \\
\hline & & Adaptability to $\mathrm{cl}$ & ange & 2 & 2 & 3 & 1 \\
\hline & & Rotational leadership & pabilities & 2 & 1 & 1 & 4 \\
\hline & & Years of experience participating in devel & pment cooperation projects. & 2 & 2 & 1 & 3 \\
\hline & & Technical knowledge & icquired & 1 & 1 & 1 & 3 \\
\hline & & Project motivat & & 1 & 1 & 1 & 1 \\
\hline & & Awareness of the situation to be impr & ved/resolved/changed & 1 & 1 & 1 & 1 \\
\hline & & Critical thinki & & 1 & 1 & 1 & 2 \\
\hline & & Active participa & on & 1 & 1 & 1 & 2 \\
\hline & & Trust buildin & & 1 & 1 & 1 & 3 \\
\hline & & Organizational cap & bility & 1 & 1 & 1 & 3 \\
\hline & & Project management $\mathrm{e}$ & perience & 1 & 1 & 1 & 3 \\
\hline & & Experience in development cooperat & on project management. & 2 & 1 & 1 & 3 \\
\hline Priority Order & Factors & Component & & $\mathrm{C}$ & EU & IDB & BP \\
\hline \multirow{3}{*}{$6^{\circ}$} & \multirow{3}{*}{ Additionality } & Training/advice and technical support $t$ & the beneficiary population & 3 & 3 & 2 & 5 \\
\hline & & Establishment of monitoring and $\mathrm{e}$ & aluation mechanisms & 3 & 3 & 1 & 3 \\
\hline & & Creation of favorable condition & to maintain results & 3 & 3 & 1 & 4 \\
\hline
\end{tabular}

Very necessary: 1; Necessary: 2; Partially required: 3; Neither necessary nor unnecessary: 4; Not necessary: 5.

\subsection{Methodologies}

The ideal methodology for development cooperation projects depends on many factors. These depend on the type of project, the duration, the sector to which it is applied, among other factors. According to interviews with some participants, it is often the consultants or the IDB team who decide which methodology to use based on their expertise. That is why the Executing Unit always chooses a Project Director, since he or she is the main contact with whom the coordination to manage and execute the project will take place.

However, from the research, it turned out that the hybrid methodology is considered the best option. This is because this methodology combines the best practices of classic methodologies and the agile world. Secondly, the Critical Chain is chosen on many occasions and then, the preference for using agile and traditional methodologies was observed, in that order, respectively (Figure 6). 


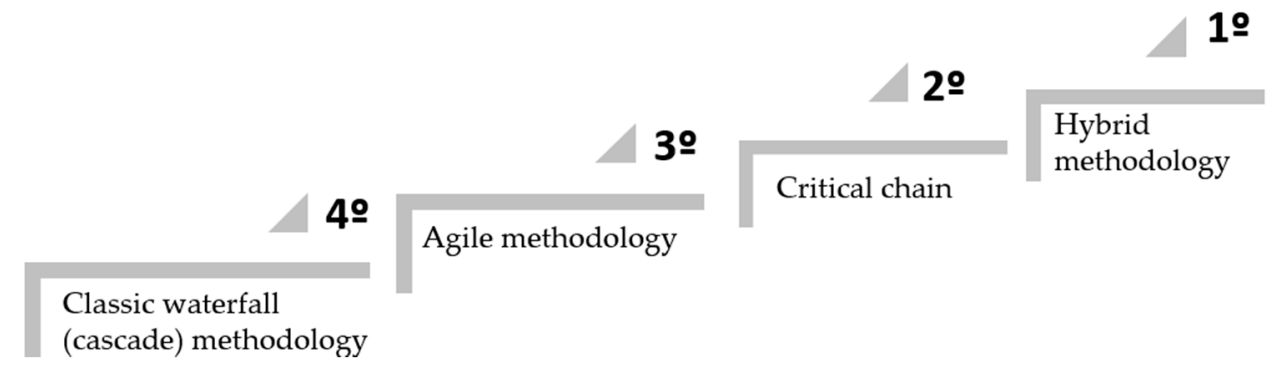

Figure 6. Order of ideal methodologies to be applied in development cooperation projects. Source: adapted from [4].

\section{Conclusions}

This research focused mainly on identifying those factors and their components that influence the success of development cooperation projects. In this way, it was possible to present a model that also relates the roles involved (Table 11). In order to meet each of the objectives, an exhaustive literature review was carried out. Among the authors who stand out for having conducted research that enriched the present study is José Antonio Monje, who in his research addresses the different perceptions of the actors involved in the projects to define the key factors such as the achievement of objectives, the perception of success, the satisfaction of expectations and levels of participation [34]. Diallo and Thuillier, Muro and Rodriguez are also noteworthy as authors of the definition of critical factors that are closely aligned with the one proposed in the logical framework of the research, who base the presence of efficiency, effectiveness, risk management, sustainability and relevance as relevant to ensure the success of cooperation projects $[11,12,14]$. Meanwhile, concerning the application of the methodology, Charles Ragin has been the main guide for his development of the software package for fuzzy set analysis (fsQCA) [23]. In general, the research carried out by the aforementioned authors complemented very well with the other authors, since they provided an enriching contribution to the literature related to the objectives proposed.

\subsection{Main Contributions}

Since 2008, the IDB has been working with the Development Effectiveness Framework (DEF) tool, which ensures that projects produce tangible and positive results for beneficiaries by promoting good practices for designing, implementing, and evaluating projects based on four principles: alignment, effectiveness, efficiency, and risk and sustainability [15]. Despite the evaluation obtained with these pillars, the model of the present research proposed to perform a deeper analysis to bring closer to reality the real results obtained from the project, not only from start to finish, but also invites one to take more balanced, sustainable, and long-term actions. The model provided in Table 11 shows the horizontal relationship between the different actors involved in multilateral projects, who must meet a certain profile for the results to be successful.

With the analysis of relationships between variables and causality, it can be concluded that the effectiveness factor has a significant relationship with the success of a development cooperation project; however, this could not be possible without good sustainability and risk management foreseen in the development of the projects. This confirms the first hypothesis, which highlights the importance of improving the analysis of the IDB's Development Effectiveness Matrix. To evaluate the performance of financing operations, according to the perspective of the different roles involved, the order of importance of the factors is effectiveness, sustainability, relevance, risk management, technical and motivational capacities, and additionality, respectively, and that these factors and their components are key to the success of development cooperation projects, which is why they should be included in the evaluation of the Development Effectiveness Framework. 
With respect to the second hypothesis, from the research it was possible to verify the high commitment expected from the different roles with their respective responsibilities, which was reflected in the results of the evaluation made to the different actors, who, according to their perspective, proceeded to evaluate the other roles. Finally, the third hypothesis of the research, it could be concluded that there is no ideal methodology to apply to multilateral projects, since many factors are involved in deciding on one; however, according to the experience of the participants for their years of work and collaboration, the hybrid methodology is the one that is more friendly to be applied to projects.

In general terms, from the analysis of all development cooperation projects and the subsequent fuzzy analysis, it was found that risk management is a necessary and sufficient condition for success in this type of project. Risk management has not only become a necessity nowadays but improving risk management will increase sustainability in project management, the main factors for a successful project. In addition, the performance of each role will be reflected and will greatly influence the success or failure of development cooperation projects. Therefore, it is important to maintain timely communication among them and promote the collaboration of people who have much or little influence and interest in the project to generate awareness and total involvement. While it is true that some stakeholders have a positive or negative influence on the project, with good judgment and treatment of the information that is handled, the negative effects that could be generated should be mitigated, so appropriate communication strategies should be generated for all stakeholders groups.

\subsection{Main Challenges}

The main difficulty faced by the research has been the limited time to carry out the studies, in which it is not possible to apply and test the model to see its results. Concerning the limitations, it can be mentioned that there was too little participation to generalize the results in Latin America. Although mail was sent to the 26 IDB representations in Latin American countries and a total of 35 professionals were contacted through LinkedIn, there were only 48 people who assumed the role of the stakeholder matrix. However, it is important to highlight their good participation in providing more information. Likewise, the responses were influenced by and limited to political, social, cultural, and economic factors of the country. The perspective that an individual from an upper-middle-income country and a middle-income country has differed. Finally, the processing time to analyze the influence of the components of certain factors on others was incalculable and the program stopped working.

\subsection{Proposals for Future Lines of Research}

It is recommended that the research be extended to more geographic territories, to observe whether the perspective that professionals have on the factors proposed in this research does not vary over time or, in any case, whether it is important to include any other factor not foreseen in the theoretical framework.

Regarding the research itself, it is proposed to carry out a statistical-descriptive and fuzzy study of the different roles involved in the same project and to compare the results obtained by applying the fuzzy methodology with other actors in projects belonging to the same sector. In this way, it will be possible to identify the appropriate methodology for each type of project. Concerning the forms, the professionals' evaluation of their role should be included. The above deepen the comparison that other roles have on oneself.

Finally, this research is only a stepping stone to contribute to the 2030 Agenda for Sustainable Development and the achievement of the Sustainable Development Goals. A joint effort must be made between governments, their policies, the private sector, and, above all, to encourage the participation of civil society to achieve the success of development cooperation projects. 
Author Contributions: Conceptualization, Y.C.S.-G., J.R. and R.R.-R.; investigation, Y.C.S.-G.; methodology, J.R. and R.R.-R.; writing—original draft preparation, Y.C.S.-G.; writing-review and editing, R.R.-R. and I.O.-M. All authors have read and agreed to the published version of the manuscript.

Funding: This research received no external funding.

Institutional Review Board Statement: Not applicable.

Informed Consent Statement: Informed consent was obtained from all subjects involved in the study.

Data Availability Statement: Data were obtained from a collaboration with the Office of Evaluation and Oversight of the IDB. The reports are not public.

Acknowledgments: The authors would like to thank to the people involved in development cooperation projects financed by the IDB for their contribution to the research.

Conflicts of Interest: The authors declare no conflict of interest.

\section{Appendix A}

Table A1. Data available for processing in the program.

\begin{tabular}{|c|c|c|c|c|c|c|c|}
\hline EFT & PTN & SGR & SUCCESS & EFT & PTN & SGR & SUCCESS \\
\hline 3.075 & 2.085 & 2.556 & 3.648 & 2.412 & 2.000 & 2.000 & 2.696 \\
\hline 2.991 & 2.047 & 2.436 & 3.410 & 3.031 & 2.038 & 2.564 & 3.577 \\
\hline 3.079 & 2.085 & 2.564 & 3.603 & 3.091 & 2.085 & 2.564 & 3.618 \\
\hline 1.576 & 1.670 & 1.471 & 1.896 & 2.934 & 1.953 & 2.544 & 1.000 \\
\hline 3.023 & 2.085 & 2.498 & 3.587 & 5.000 & 3.000 & 3.529 & 6.000 \\
\hline 2.977 & 1.915 & 2.502 & 3.462 & 3.044 & 2.085 & 2.575 & 3.584 \\
\hline 5.000 & 2.377 & 3.720 & 5.664 & 3.066 & 2.085 & 2.571 & 3.621 \\
\hline 3.056 & 2.038 & 2.510 & 3.401 & 2.969 & 1.915 & 2.436 & 3.375 \\
\hline 4.614 & 2.708 & 3.763 & 5.668 & 3.015 & 2.085 & 2.564 & 3.658 \\
\hline 4.000 & 2.000 & 3.000 & 5.000 & 2.966 & 2.085 & 2.456 & 3.618 \\
\hline 3.008 & 2.047 & 2.575 & 3.626 & 3.035 & 2.085 & 2.544 & 3.570 \\
\hline 2.977 & 1.915 & 2.502 & 3.462 & 3.063 & 2.085 & 2.521 & 3.590 \\
\hline 4.614 & 2.085 & 2.575 & 5.378 & 3.019 & 1.962 & 2.456 & 3.589 \\
\hline 1.000 & 1.000 & 1.000 & 2.478 & 3.044 & 2.708 & 2.571 & 2.969 \\
\hline 2.000 & 1.623 & 1.763 & 1.842 & 3.044 & 1.623 & 2.429 & 3.443 \\
\hline 4.012 & 2.377 & 3.280 & 4.722 & 3.059 & 2.047 & 2.548 & 3.561 \\
\hline 3.370 & 1.670 & 2.280 & 3.997 & 5.000 & 3.000 & 4.000 & 5.200 \\
\hline 5.000 & 3.000 & 4.000 & 6.000 & 2.000 & 1.000 & 1.000 & 3.478 \\
\hline 4.794 & 3.000 & 3.751 & 5.836 & 3.059 & 2.085 & 2.575 & 1.464 \\
\hline 2.969 & 1.292 & 2.425 & 3.373 & 3.023 & 1.962 & 2.544 & 3.637 \\
\hline 3.210 & 2.038 & 2.571 & 3.629 & 3.019 & 2.038 & 2.425 & 3.760 \\
\hline 4.396 & 2.708 & 3.517 & 5.016 & 1.576 & 2.047 & 1.720 & 2.513 \\
\hline 3.066 & 2.047 & 2.575 & 4.108 & 2.921 & 1.330 & 2.436 & 3.528 \\
\hline 3.057 & 1.953 & 2.498 & 3.565 & 1.000 & 2.000 & 3.000 & 1.519 \\
\hline
\end{tabular}

\section{Appendix B}

Table A2. Components and results values.

\begin{tabular}{cccccccccc}
\hline Cases & & Categories & & Results & Cases & & Categories & Results \\
\hline Participant & EFT & PTN & SGR & SUCCESS & Participant & EFT & PTN & SGR & SUCCESS \\
\hline P01 & 3.075 & 2.085 & 2.556 & 3.648 & P25 & 2.412 & 2.000 & 2.000 & 2.696 \\
P02 & 2.991 & 2.047 & 2.436 & 3.410 & P26 & 3.031 & 2.038 & 2.564 & 3.577 \\
P03 & 3.079 & 2.085 & 2.564 & 3.603 & P27 & 3.091 & 2.085 & 2.564 & 3.618 \\
P04 & 1.576 & 1.670 & 1.471 & 1.896 & P28 & 2.934 & 1.953 & 2.544 & 1.000 \\
P05 & 3.023 & 2.085 & 2.498 & 3.587 & P29 & 5.000 & 3.000 & 3.529 & 6.000 \\
P06 & 2.977 & 1.915 & 2.502 & 3.462 & P30 & 3.044 & 2.085 & 2.575 & 3.584 \\
\hline
\end{tabular}


Table A2. Cont.

\begin{tabular}{cccccccccc}
\hline Cases & & Categories & & Results & Cases & & Categories & Results \\
\hline Participant & EFT & PTN & SGR & SUCCESS & Participant & EFT & PTN & SGR & SUCCESS \\
\hline P07 & 5.000 & 2.377 & 3.720 & 5.664 & P31 & 3.066 & 2.085 & 2.571 \\
P08 & 3.056 & 2.038 & 2.510 & 3.401 & P32 & 2.969 & 1.915 & 2.436 & 3.621 \\
P09 & 4.614 & 2.708 & 3.763 & 5.668 & P33 & 3.015 & 2.085 & 2.564 \\
P10 & 4.000 & 2.000 & 3.000 & 5.000 & P34 & 2.966 & 2.085 & 2.456 \\
P11 & 3.008 & 2.047 & 2.575 & 3.626 & P35 & 3.035 & 2.085 & 2.544 \\
P12 & 2.977 & 1.915 & 2.502 & 3.462 & P36 & 3.063 & 2.085 & 2.521 \\
P13 & 4.614 & 2.085 & 2.575 & 5.378 & P37 & 3.019 & 1.962 & 2.456 \\
P14 & 1.000 & 1.000 & 1.000 & 2.478 & P38 & 3.044 & 2.708 & 2.571 \\
P15 & 2.000 & 1.623 & 1.763 & 1.842 & P39 & 3.044 & 1.623 & 2.429 \\
P16 & 4.012 & 2.377 & 3.280 & 4.722 & P40 & 3.059 & 2.047 & 2.548 \\
P17 & 3.370 & 1.670 & 2.280 & 3.997 & P41 & 5.000 & 3.000 & 4.000 \\
P18 & 5.000 & 3.000 & 4.000 & 6.000 & P42 & 2.000 & 1.000 & 1.000 \\
P19 & 4.794 & 3.000 & 3.751 & 5.836 & P43 & 3.059 & 2.085 & 2.575 \\
P20 & 2.969 & 1.292 & 2.425 & 3.373 & P44 & 3.023 & 1.962 & 2.544 \\
P21 & 3.210 & 2.038 & 2.571 & 3.629 & P45 & 3.019 & 2.038 & 2.451 \\
P22 & 4.396 & 2.708 & 3.517 & 5.016 & P46 & 1.576 & 2.047 & 1.720 \\
P23 & 3.066 & 2.047 & 2.575 & 4.108 & P47 & 2.921 & 1.330 & 2.436 \\
P24 & 3.057 & 1.953 & 2.498 & 3.565 & P48 & 1.000 & 2.000 & 3.637 \\
\hline
\end{tabular}

\section{Appendix C}

Table A3. Calibrated data for analysis.

\begin{tabular}{|c|c|c|c|c|c|c|c|c|c|}
\hline \multirow{2}{*}{$\begin{array}{c}\text { Cases } \\
\text { Participant }\end{array}$} & \multicolumn{3}{|c|}{ Categories } & \multirow{2}{*}{$\begin{array}{c}\text { Results } \\
\text { SUCCESS }\end{array}$} & \multirow{2}{*}{$\begin{array}{c}\text { Cases } \\
\text { Participant }\end{array}$} & \multicolumn{3}{|c|}{ Categories } & \multirow{2}{*}{$\begin{array}{c}\text { Results } \\
\text { SUCCESS }\end{array}$} \\
\hline & EFT & PTN & SGR & & & EFT & PTN & SGR & \\
\hline P01 & 0.49 & 0.47 & 0.49 & 0.48 & P25 & 0.35 & 0.48 & 0.34 & 0.32 \\
\hline P02 & 0.49 & 0.49 & 0.47 & 0.46 & P26 & 0.51 & 0.51 & 0.49 & 0.51 \\
\hline P03 & 0.49 & 0.47 & 0.49 & 0.51 & $\mathrm{P} 27$ & 0.48 & 0.47 & 0.49 & 0.49 \\
\hline P04 & 0.19 & 0.36 & 0.22 & 0.19 & $\mathrm{P} 28$ & 0.47 & 0.46 & 0.51 & 0.10 \\
\hline P05 & 0.49 & 0.47 & 0.49 & 0.51 & P29 & 0.06 & 0.07 & 0.14 & 0.06 \\
\hline P06 & 0.48 & 0.45 & 0.49 & 0.47 & P30 & 0.51 & 0.47 & 0.49 & 0.51 \\
\hline P07 & 0.06 & 0.29 & 0.10 & 0.09 & P31 & 0.49 & 0.47 & 0.49 & 0.49 \\
\hline P08 & 0.49 & 0.49 & 0.49 & 0.46 & P32 & 0.48 & 0.45 & 0.47 & 0.45 \\
\hline P09 & 0.10 & 0.14 & 0.09 & 0.09 & P33 & 0.49 & 0.47 & 0.49 & 0.48 \\
\hline P10 & 0.20 & 0.48 & 0.3 & 0.17 & P34 & 0.48 & 0.47 & 0.47 & 0.49 \\
\hline P11 & 0.49 & 0.49 & 0.49 & 0.49 & P35 & 0.51 & 0.47 & 0.51 & 0.51 \\
\hline $\mathrm{P} 12$ & 0.48 & 0.45 & 0.49 & 0.47 & P36 & 0.49 & 0.47 & 0.49 & 0.49 \\
\hline P13 & 0.10 & 0.47 & 0.49 & 0.13 & P37 & 0.49 & 0.47 & 0.47 & 0.49 \\
\hline P14 & 0.11 & 0.17 & 0.13 & 0.28 & P38 & 0.51 & 0.14 & 0.49 & 0.37 \\
\hline P15 & 0.26 & 0.35 & 0.28 & 0.19 & P39 & 0.51 & 0.35 & 0.46 & 0.47 \\
\hline P16 & 0.20 & 0.29 & 0.20 & 0.22 & P40 & 0.49 & 0.51 & 0.49 & 0.49 \\
\hline P17 & 0.39 & 0.36 & 0.42 & 0.39 & P41 & 0.06 & 0.07 & 0.06 & 0.14 \\
\hline P18 & 0.06 & 0.07 & 0.06 & 0.06 & P42 & 0.26 & 0.17 & 0.13 & 0.48 \\
\hline P19 & 0.08 & 0.07 & 0.09 & 0.07 & $\mathrm{P} 43$ & 0.49 & 0.47 & 0.49 & 0.14 \\
\hline P20 & 0.48 & 0.24 & 0.46 & 0.45 & $\mathrm{P} 44$ & 0.49 & 0.47 & 0.51 & 0.49 \\
\hline P21 & 0.44 & 0.49 & 0.49 & 0.49 & P45 & 0.49 & 0.49 & 0.46 & 0.45 \\
\hline $\mathrm{P} 22$ & 0.13 & 0.14 & 0.14 & 0.16 & P46 & 0.19 & 0.51 & 0.27 & 0.29 \\
\hline P23 & 0.49 & 0.51 & 0.49 & 0.36 & P47 & 0.47 & 0.25 & 0.47 & 0.49 \\
\hline $\mathrm{P} 24$ & 0.51 & 0.46 & 0.49 & 0.49 & P48 & 0.11 & 0.48 & 0.3 & 0.15 \\
\hline
\end{tabular}




\section{References}

1. Castro, A.M.; Becerra, L.E.; Romero, E. Factores de éxito en proyectos de cooperación. Caso Universidad Industrial de Santander. Rev. Cienc. Estratégicas 2016, 24, 413-429. [CrossRef]

2. Sotillo, J.A. El papel de la Unión Europea en la cooperación para el desarrollo: Opciones y límites al vínculo entre gobernanza y desarrollo. Cuad. Eur. Deusto 2011, 45, 149-175. [CrossRef]

3. World Bank Country and Lending Groups-World Bank Data Help Desk. Available online: https: / / datahelpdesk.worldbank. $\mathrm{org}$ / knowledgebase/articles/906519-world-bank-country-and-lending-groups (accessed on 18 May 2021).

4. Surco, Y. Análisis Cualitativo Comparativo de Proyectos de Cooperación al Desarrollo Financiados por el BID en Latinoamérica. Master's Thesis, E.T.S.I. Industriales, UPM, Madrid, Spain, 2021. Available online: https:/ / oa.upm.es/68709/ (accessed on 26 November 2021).

5. Inter-American Development Bank-Revisión de OVE de los Informes de Terminación de Proyecto y los Informes Ampliados de Supervisión: Ciclo de validación 2020. Available online: https:/ / publications.iadb.org/es/revision-de-ove-de-los-informes-determinacion-de-proyecto-y-los-informes-ampliados-de-1 (accessed on 15 May 2021).

6. Pinto, J.; Slevin, D. Critical Factors in Successful Project Implementation. T-EM 1987, 34, 22-27. [CrossRef]

7. Belassi, W.; Tukel, O.I. A new framework for determining critical success/failure factors in projects. Int. J. Proj. Manag. 1996, 14, 141-151. [CrossRef]

8. Westervel, E. The project excellence model: Linking success criteria and critical success factors. Int. J. Proj. Manag. 2003, 21, 411-418. [CrossRef]

9. Fortune, J.; White, D. Framing of project success critical success factors by a system model. Int. J. Proj. Manag. 2006, 24, 53-65. [CrossRef]

10. Baccarani, D. The logical framework method for defining project success. Proj. Manag. J. 1999, 30, 25-32. [CrossRef]

11. Rodríguez, R.; Hesse, M. Al andar se Hace Camino. Guía Metodológica Para Desencadenar Procesos Autogestionarios Alrededor de Experiencias Agroecológicas; Kimpres Ltda: Bogotá, Colombia, 2000.

12. Diallo, A.; Thuillier, D. The success dimensions of international development proj-ects: The perceptions of African project coordinators. Int. J. Proj. Manag. 2004, 22, 19-31. [CrossRef]

13. Ba Khang, D.; Lin Moe, T. Success criteria and factors for international development projects: A life-cycle-based framework. Proj. Manag. J. 2008, 39, 72-84. [CrossRef]

14. Inter-American Development Bank-Efectividad en el Desarrollo. Available online: https://www.iadb.org/es/oficina-deplanificacion-estrategica-y-efectividad-en-el-desarrollo/efectividad-en-el-desarrollo (accessed on 15 May 2021).

15. Gasché, J.; Vela, N. Sociedad Bosquesina. Tomo II. ¿Qué Significa para los Bosquesinos Autonomía, Libertad, Autoridad y Democracia? Instituto de Investigaciones de la Amazonía Peruana: Lima, Peru, 2012.

16. Muro, J. La internacionalización multilateral: Estrategia, metodología y técnicas para acometer con éxito los proyectos financiados por los organismos multilaterales. Manuales ICEX CECO 2012, 328. Available online: https:/ /www.icex.es/icex/GetDocumento? dDocName=DAX2019817298\&site=icexES (accessed on 15 May 2021).

17. Lavagnon, A.; Diallo, A.; Thuillier, D. The empirical relationship between success factors and dimensions: The perspectives of World Bank project supervisors and managers. Int. J. Proj. Manag. 2011, 4, 711-719.

18. Mohareb, M. Critical Success Factors of International Development Projects in the Education Sector in Egypt: Community Schools as a Case Study. Master's Thesis, School of Global Affairs and Public Policy, American University in Cairo, Cairo, Egypt, 2017.

19. Quijano, S. Dirección de Recursos Humanos y Consultoría en las Organizaciones, 1st ed.; Icaria Editorial: Barcelona, Spain, 2006.

20. Mondelo, E.; Sánchez, R. PM4R Agile. Guía Práctica. Banco Interamericano de Desarrollo. 2019. Available online: https:// connectamericas.com/sites/default/files/articles_files/Guia_Practica\%20PM4R_Agile.pdf (accessed on 20 December 2021).

21. Saunders, M.; Lewis, P.; Thornhill, A. Research Methods for Fusiness Students, 7th ed.; Pearson: Harlow, UK, 2016. Available online: https:/ / www.pearson.com/uk/educators/higher-education-educators/program/Saunders-Research-Methods-forBusiness-Students-7th-Edition/PGM1089011.html (accessed on 20 December 2021).

22. Kent, R.; Olsen, W. Using fsQCA. A Brief Guide and Workshop for Fuzzy-Set Qualitative Comparative Analysis; University of Stirling: Stirling, UK, 2008. Available online: http://hummedia.manchester.ac.uk/institutes/cmist/archive-publications/workingpapers/2008/2008-10-teaching-paper-fsqca.pdf (accessed on 20 December 2021).

23. Ragin, C. User's Guide to Fuzzy-Set/Qualitative Comparative Analysis; University of California: Irvine, CA, USA, 2017.

24. Sakaran, U.; Bougie, R. Research Methods for Business: A Skill Building Approach, 7th ed.; 2016. Available online: https://www.wiley. com/en-ie/Research+Methods+For+Business:+A+Skill+Building+Approach,+7th+Edition-p-9781119266846 (accessed on 20 December 2021).

25. Legewie, N. An introduction to applied data analysis with Qualitative Comparative Analysis (QCA). FQS 2013, $14,45$.

26. Ragin, C. Redesigning Social Inquiry: Fuzzy Sets and Beyond; University of Chicago Press: Chicago, IL, USA, 2008.

27. Rodríguez-Rivero, R.; Ortiz-Marcos, I.; Romero, J.; Ballesteros-Sánchez, L. Finding the Links between Risk Management and Project Success: Evidence from International Development Projects in Colombia. Sustainability 2020, 12, 9294. [CrossRef]

28. Fiss, P.C. Building better causal theories: A Fuzzy set approach to typologies in organization research. Acad. Manag. J. 2011, 54, 393-420. [CrossRef]

29. Hervas-Oliver, J.L.; Sempere-Ripoll, F.; Arribas, I. Asymmetric modeling of organizational innovation. J. Bus. Res. 2015, 68, 2654-2662. [CrossRef] 
30. Ragin, C. Set relations in social research: Evaluating their consistency and coverage. Political Anal. 2006, 14, 291-310. [CrossRef]

31. Woodside, A.G. Moving beyond multiple regression analysis to algorithms: Calling for a paradigm shift from symmetric to asymmetric thinking in data analysis and crafting theory. J. Bus. Res. 2013, 66, 463-472. [CrossRef]

32. Rodríguez-Rivero, R. Metodología del Marco Lógico con Enfoque de Gestión de Riesgos para Mejorar la Eficacia de los Proyectos de Cooperación al Desarrollo. Ph.D. Thesis, E.T.S.I. Industriales, UPM, Madrid, Spain, 2019.

33. Romero, J.J. Identificación de los elementos clave de la estrategia competitiva en el modelo de negocio aeroportuario en un contexto liberalizado de competencia internacional: Aplicación al caso del Reino Unido. Ph.D. Thesis, E.T.S.I. Industriales, UPM, Madrid, Spain, 2019.

34. Monje, J. Antropología del desarrollo y factores críticos para el éxito de los proyectos de cooperación internacional. AIBR-Rev. Antropol. Iberoam. 2018, 13, 93-117. 